\title{
In situ simulation as a quality improvement initiative
}

\author{
Phani Kiran Yajamanyam, ${ }^{1}$ Dalbir Sohi ${ }^{2}$
}

${ }^{1}$ Department of Neonatology, Birmingham Women's Hospital, Birmingham, UK ${ }^{2}$ Department of Paediatrics, North Middlesex University Hospital, London, UK

\section{Correspondence to}

Dr Phani Kiran Yajamanyam, Neonatal Unit, Birmingham Women's Hospital, Mindelsohn way, Birmingham B15 2TG, UK ; pyajamanyam@nhs.net

Received 9 June 2014 Revised 2 December 2014 Accepted 4 March 2015 Published Online First 7 April 2015

\section{CrossMark}

To cite: Yajamanyam PK, Sohi D. Arch Dis Child Educ Pract Ed 2015;100:162-163.

\section{ABSTRACT}

Simulation-based learning has gained recent recognition as a means of improving patient safety. In situ simulation, that is conducting simulation training in actual clinical environment, is a novel approach to detecting deficiencies in healthcare systems, termed as latent safety threats (LSTs). We implemented in situ simulation training as a quality improvement initiative and were able to detect several LSTs, thus improving patient safety.

\section{SUMMARY}

Implementation of an in situ simulation training (InST) programme to improve acute paediatric care in a district general hospital (DGH).

\section{PROBLEM}

Critical incident analysis of an adverse event that happened in the paediatric accident and emergency department (A\&E) at North Middlesex Hospital identified a latent safety threat (LST) as a potential contributing factor.

\section{AIMS}

Triggered by this review, InST was integrated into the paediatric teaching programme as a quality improvement (QI) initiative with the (SMART) aim of (S) reducing the occurrence of LSTs in paediatric $A \& E$ and the neonatal unit (NNU) by $(\mathrm{M}, \mathrm{A})$ detecting specific LSTs during the InST as (R) it can improve patient care. We piloted InST for 10 months to measure its impact $(\mathrm{T})$.

\section{MAKING A CASE FOR CHANGE}

A paediatric simulation team (who had received training in implementation and facilitation of simulation training) comprising a consultant paediatrician, a resuscitation officer and a senior paediatric trainee was instigated. As InST happens in actual clinical environments, approval of the senior clinical and management teams in paediatric A\&E and NNU was obtained by presenting the evidence supporting the role of InST in detecting $\mathrm{LSTs}^{1}{ }^{2}$ and improving multidisciplinary team working. ${ }^{1-3}$ The local National Health Service trust's postgraduate education department fully supported the simulation training programme. Introduction of InST was communicated to all members of the paediatric and neonatal teams over few weeks via trust emails, posters and face-to-face updates during team meetings.

\begin{tabular}{lll}
\hline Error identified & Remedial action & Preventing LST recurrence \\
\hline Paraldehyde out of stock in A\&E & Restocked & $\begin{array}{l}\text { Included in pharmacy stock } \\
\text { checks }\end{array}$ \\
$\begin{array}{lll}\text { Bag and mask in paediatric resuscitation area } \\
\text { not connecting to oxygen source }\end{array}$ & $\begin{array}{l}\text { Suitable connector provided by } \\
\text { medical physics }\end{array}$ & $\begin{array}{l}\text { Included in paediatric A\&E } \\
\text { check sheet }\end{array}$ \\
$\begin{array}{l}\text { Intramuscular adrenaline 1:1000 not available } \\
\text { in paediatric A\&E }\end{array}$ & $\begin{array}{l}\text { Restocked } \\
\text { Resuscitaire out of stock on NNU }\end{array}$ & $\begin{array}{l}\text { Included in paediatric A\&E } \\
\text { check sheet }\end{array}$ \\
$\begin{array}{l}\text { Junior medical staff unaware of 'Resus grab } \\
\text { bag' on NNU }\end{array}$ & Measures taken to inform staff \\
$\begin{array}{l}\text { Junior medical staff unaware of location of } \\
\text { resuscitation equipment on NNU }\end{array}$ & $\begin{array}{l}\text { Staff orientation organised } \\
\text { implemented and audited }\end{array}$ \\
$\begin{array}{l}\text { Need for educating paediatric nursing staff } \\
\text { about continuous positive airway pressure }\end{array}$ & $\begin{array}{l}\text { Educational package introduced } \\
\text { by the nurse educators }\end{array}$ & Include in future inductions \\
\hline $\begin{array}{l}\text { A\&E, accident and emergency department; LST, latent safety threat; NNU, neonatal unit. } \\
\text { Regular training sessions }\end{array}$
\end{tabular}




\section{IMPROVEMENTS ACHIEVED}

Twenty-one sessions were conducted in paediatric A\&E and eight on NNU. Ninety-eight participants took part in InST. None of the sessions were interrupted due to clinical emergencies. Seven LSTs were identified, which are detailed in the following table. These errors were immediately reported to the trust's clinical governance team via the trust's incident reporting system.

\section{LEARNING}

This QI project was successful in detecting LSTs, thus improving acute patient care. Prior communication and support from all relevant departments in the trust, availability of appropriate expertise and close links with the clinical governance system of the trust were vital to our success.

Structured scenarios with predetermined learning objectives simulating common emergencies were used $^{4}$ (examples can be found on the Royal College of Paediatrics and Child Health website). The simulated scenarios were sometimes replicated from real emergencies or clinical incidents that had occurred in the trust. Low-fidelity Laerdal resuscitation manikins that are widely available in most DGHs were used. A typical simulation exercise lasted approximately $45 \mathrm{~min}$ with the clinical scenario conducted for 10-12 min. Following each individual InST session, the lead facilitator maintained a log of LSTs identified. Participants were also asked to provide reflective notes highlighting specific learning points to be included in their personal portfolio of learning.

We used the trust's clinical governance system to measure the impact of InST by identifying recurrence of any adverse events or near misses that could be attributed to LSTs previously identified. However, we believe an ideal InST programme would include repeating the process (that identified LSTs) few weeks to months after the initial exercise to investigate whether the LSTs had resolved completely. We did not follow this process during the 10 -month pilot due to constraints on time and resources; however, we are currently implementing the replication process to evaluate the impact of InST.

This QI initiative provides evidence to support the implementation of InST in DGHs to improve patient safety by ensuring LSTs are detected prior to real patient encounters.

\section{NEXT STEPS}

We have continued to implement weekly InST within the paediatrics department and have disseminated our findings during a trust-wide patient safety conference. Our results were received very well, and other departments (eg, anaesthetics) are planning to introduce regular InST.

Contributors PKY and DS were involved in conducting the simulation training during the study period described. PKY wrote the initial draft manuscript and was involved in its revision. DS was involved in the organisation of training and was responsible for the revision of the manuscript.

Competing interests None.

Provenance and peer review Not commissioned; externally peer reviewed.

\section{REFERENCES}

1 Patterson MD, Geis GL, Falcone RA, et al. In-situ simulation: detection of safety threats and teamwork training in a high risk emergency department. BMJ Qual Saf 2013;22:468-77.

2 Walker ST, Sevdalis N, McKay A, et al. Unannounced in situ simulations: integrating training and clinical practice. BMJ Qual Saf 2013;22:453-8.

3 Fialkow MF, Adams CR, Carranza L, et al. An in situ standardized patient-based simulation to train postpartum hemorrhage and team skills on a labor and delivery unit. Simul Healthc 2014;9:65-71.

4 Simulation and Technology Enhanced Learning Resources, Royal College of Paediatrics and Child Health. http://www. rcpch.ac.uk/training-examinations-professional-development/ postgraduate-training/simulation-and-technology-enhan (accessed 2 Dec 2014). 